\title{
Circulatory changes induced by isovolumic increase in red cell mass in fetal lambs
}

\author{
G Teyssier, J C Fouron, S E Sonesson, P Bonnin, A Skoll
}

\begin{abstract}
Aim-To verify whether extra uterine changes in total peripheral vascular resistance and cardiac output, caused by raised haematocrit, occur in fetal life and if they can be documented using conventional ultrasound techniques.

Methods-An exchange transfusion with packed red cells was performed on five fetal lambs at 140 days of gestation (weight 3.44, SD $0.48 \mathrm{~kg}$ ); three others were used as controls. The haematocrit was raised from $44 \pm 3$ to 64 (SD2)\%.

Results-Body temperature, blood gas, and $\mathrm{pH}$ remained within normal limits. Blood viscosity increased from $5.3(0.3)$ to $9.6(1.6) \mathrm{cps}$. Combined cardiac output fell to $30 \%$ of its initial value. The pulsatility index (PI) remained unchanged in the umbilical artery (0.66, SD 0.1$)$ and descending aorta (1.3, SD 0.3). A significant positive correlation was found between haematocrit and PI only in the carotid $\operatorname{artery}(\mathrm{r}=0.67, \mathrm{p}<0.01)$.

Conclusion-In the fetus, as in adults, an increase in blood viscosity is associated with a fall in cardiac output. However, the low resistance and the relative inertia of the placental vascular bed blunt the velocimetric changes that could be induced in the lower body vascular system by an increase in resistance. Such changes were observed only in the carotid artery. These results could be of interest in the Doppler monitoring of human fetuses at risk of an abnormal increase in their haematocrit.
\end{abstract}

(Arch Dis Child Fetal Neonatal Ed 1998;79:F180-F184)

Keywords: haematocrit; viscosity;cerebral artery; umbilical artery

The Fetal Cardiology

Unit

Pediatric Cardiology

Service

Sainte-Justine Hospital

3175 Côte Ste

Catherine

University of Montreal

Quebec

Canada H3T 1C5

G Teyssier

J C Fouron

S E Sonesson

P Bonnin

Department of

Obstetrics

A Skoll

Correspondence to:

Dr Jean-Claude Fouron.

Email: fouron@sympatico.ca

Accepted 17 May 1998 incorporated in clinical practice. ${ }^{12}$ Yet in extrauterine life, an increase in red cell mass and blood viscosity decreases cardiac output and raises total peripheral resistance. ${ }^{34}$

This study aimed to verify whether the haemodynamic changes observed after birth could be documented during fetal life, thus providing ultrasonographic criteria that could be integrated in the monitoring of pregnancies where high fetal haematocrit is suspected.

\section{Methods}

Eight pregnant ewes of mixed breed, at around 140 days of gestation (145-150 days) were used in this study. After fasting for 48 hours, during which water was given ad libitum, the animals were anaesthetised with intravenous injections of ketamine hydrochloride ( $3 \mathrm{mg} / \mathrm{kg}$ ) and sodium pentobarbital (2 $\mathrm{mg} / \mathrm{kg})$ given alternately at around 20 minute intervals. The uterus was exposed through a median laparotomy to the parietal wound, keeping the organ inside the abdominal cavity. A hind limb of the fetus was pulled out of the cavity, allowing a polyvinyl catheter to be introduced into the femoral vein. The fetus was then completely exposed and respiration prevented by covering its head with a rubber glove filled with warm saline. A 21 gauge needle (Medicut) was introduced into the right carotid artery for arterial blood gas and pressure measurements. Fetal temperature was kept within normal limits (between 38.5 and $39.5^{\circ} \mathrm{C}$ ) by radiant heat. During the entire experiment, the animal was kept very close to the surgical incision, leaving only a few centimetres of umbilical cord outside the uterus. All fetuses were weighed at the end of the study.

Ultrasonic evaluations were obtained using a Sonos 100-Hewlett-Packard echocardiograph equipped with real time imaging and pulsed Doppler capabilities. Doppler investigation was guided by two dimensional imaging of the vascular structure using a $5 \mathrm{MHz}$ mechanical transducer. The Doppler flow velocity studies were carried out through a subxyphoid approach, allowing visualisation of ascending and thoracic aorta and, with a slight tilting of the transducer, the main pulmonary artery. ${ }^{5}$ Flow velocity through both semilunar valves could be recorded looking for the best spectral envelope and the highest peak velocities, with an angle less than 20 degrees between the ultrasound beam and the presumed orientation of the blood stream. The diameters of the aorta and pulmonary arteries were measured on the real time images. To reduce sources of variability, five diameter measurements were averaged and the same value was used for all three steps 
Table 1 Physiological data for three levels of haematocrit obtained

\begin{tabular}{|c|c|c|c|c|c|c|c|c|c|c|c|c|c|c|}
\hline$I D$ & Steps & $\begin{array}{l}\text { Weight } \\
(\mathrm{kg})\end{array}$ & $\begin{array}{l}\text { Haemoglobin } \\
(\mathrm{g} / \mathrm{l})\end{array}$ & $\begin{array}{l}\text { AHaemoglobin } \\
(\mathrm{g} / \mathrm{l})\end{array}$ & $\begin{array}{l}H T C \\
(\%)\end{array}$ & $\begin{array}{l}\triangle H T C \\
(\%)\end{array}$ & $\begin{array}{l}\text { VISC } \\
\text { (cps) }\end{array}$ & $\begin{array}{l}\triangle V I S C \\
\text { (cps) }\end{array}$ & $p H$ & $\Delta p H$ & $\begin{array}{l}\mathrm{PCO}_{2} \\
\text { (torr) }\end{array}$ & $\begin{array}{l}\triangle \mathrm{PCO}_{2} \\
\text { (torr) }\end{array}$ & $\begin{array}{l}\mathrm{PO}_{2} \\
\text { (torr) }\end{array}$ & $\begin{array}{l}\mathrm{APO}_{2} \\
\text { (torr) }\end{array}$ \\
\hline LAO & $1 \mathrm{~B}$ & 3.8 & 12.4 & & 47 & & 5.56 & & 7.35 & & 34.4 & & 25.3 & \\
\hline NOR & 1B & 3.2 & 14.2 & & 45 & & 5.08 & & & & & & 20.7 & \\
\hline QUE & 1B & 3 & 14.6 & & 45.5 & & 5.59 & & 7.21 & & 41 & & 22.2 & \\
\hline TAN & $1 \mathrm{~B}$ & 3 & 13.2 & & 45 & & 5.33 & & 7.36 & & 36.2 & & 18 & \\
\hline URU & $1 \mathrm{~B}$ & 4.2 & 10.3 & & 38 & & 4.70 & & 7.36 & & 33.9 & & 16.0 & \\
\hline LAO & $2 \mathrm{M}$ & 3.8 & 17.2 & 4.8 & 57 & 10 & 6.92 & 1.36 & 7.29 & -0.06 & 41.9 & 7.5 & 26.1 & 0.8 \\
\hline NOR & $2 \mathrm{M}$ & 3.2 & 17.8 & 3.6 & 58 & 13 & & & & & 37 & & 25 & 4.3 \\
\hline QUE & $2 \mathrm{M}$ & 3 & 17.7 & 3.1 & 52.5 & 7 & 7.19 & 1.6 & 7.3 & 0.09 & 33.3 & -7.7 & 19 & -3.2 \\
\hline TAN & $2 \mathrm{M}$ & 3 & 17 & 3.8 & 57 & 12 & 7.19 & 1.86 & 7.22 & -0.14 & 50 & 13.8 & 23.1 & 5.1 \\
\hline URU & $2 \mathrm{M}$ & 4.2 & 16.6 & 6.3 & 57 & 19 & 6.3 & 1.6 & 7.36 & 0 & 37.1 & 3.2 & 15.3 & -0.7 \\
\hline LAO & $3 \mathrm{H}$ & 3.8 & 19.5 & 7.1 & 65 & 18 & 11.1 & 5.54 & 7.29 & -0.06 & 34.2 & -0.2 & 24.6 & -0.7 \\
\hline NOR & $3 \mathrm{H}$ & 3.2 & 20.6 & 6.4 & 65 & 20 & & & 7.32 & & 35.1 & & 23.4 & 2.7 \\
\hline QUE & $3 \mathrm{H}$ & 3 & 21.5 & 6.9 & 63 & 17.5 & 10.21 & 4.62 & 7.33 & 0.12 & 43.2 & 2.2 & 16.5 & -5.7 \\
\hline TAN & $3 \mathrm{H}$ & 3 & 20.4 & 7.2 & 67 & 22 & 9.99 & 4.66 & 7.29 & -0.07 & 50.2 & 14 & 18.1 & 0.1 \\
\hline \multirow[t]{7}{*}{ URU } & $3 \mathrm{H}$ & 4.2 & 18.2 & 7.9 & 61 & 23 & 6.92 & 2.22 & 7.39 & 0.03 & 44.7 & 10.8 & 12 & -4 \\
\hline & AVG (B) & 3.4 & 12.9 & & 44.1 & & 5.25 & & 7.32 & & 36.4 & & 20.4 & \\
\hline & STD & 0.5 & 1.71 & & 3.51 & & 0.37 & & 0.07 & & 3.2 & & 3.6 & \\
\hline & AVG $(\mathrm{M})$ & & 17.3 & 4.32 & 56.3 & 12.2 & 6.9 & 1.61 & 7.29 & -0.03 & 39.9 & 4.2 & 21.7 & 1.26 \\
\hline & STD & & 0.5 & 1.27 & 2.17 & 4.44 & 0.42 & 0.2 & 0.06 & 0.1 & 6.4 & 9.05 & 4.5 & 3.46 \\
\hline & $\operatorname{AVG}(\mathrm{H})$ & & 20.0 & 7.1 & 64.2 & 20.1 & 9.56 & 4.3 & 7.32 & 0 & 41.5 & 6.7 & 18.9 & -1.52 \\
\hline & STD & & 1.25 & 0.54 & 2.28 & 2.41 & 1.82 & 1.42 & 0.04 & 0.09 & 6.8 & 6.78 & 5.2 & 3.34 \\
\hline $\begin{array}{l}\text { Friedman } \\
\text { ANOVA }\end{array}$ & $\mathrm{p}$ & & 0.01 & & 0.01 & & 0.05 & & $>0.05$ & & $>0.05$ & & $>0.05$ & \\
\hline
\end{tabular}

B, $\mathrm{M}$ and $\mathrm{H}$ : basal, moderate, and high haematocrit, respectively; HTC: haematocrit; VISC: viscosity; $\Delta$ : differences.

of the experimental protocol. Blood velocities through the umbilical artery and the left carotid artery were also recorded, using a 7.5 $\mathrm{MHz}$ transducer. The ultrasound studies were recorded on videotapes for further analysis. From these recordings, the following variables were calculated: blood flow through the main pulmonary artery and ascending aorta (time integral of maximum velocities $\times$ valvular surface area $\times$ heart rate) and pulsatility indices in the umbilical and carotid arteries as well as descending aorta [(peak systolic velocity- end diastolic velocity)/mean velocity]. ${ }^{6}$ All calculations were based on measurements of at least five consecutive complexes.

Arterial $\mathrm{pH}, \mathrm{PO}_{2}, \mathrm{PCO}_{2}$, as well as haemoglobin concentrations were measured on samples of $0.8 \mathrm{ml}$ of carotid blood using an ABL30 blood gas analyser (radiometer, Copenhagen, Denmark). On the same sample, blood haematocrit and viscosity were obtained, the first by microcentrifugation, the second with a WellsBrookfield cone-plate viscometer, as described before. ${ }^{7}$ Viscosity values were obtained at shear rates of $11.5,23$, and 90 seconds. The influence of haematocrit was similar at all shear rates and only values obtained at 11.5 seconds will be reported. Arterial blood pressure was recorded on a Gould multichannel recorder, model TA240.

EXPERIMENTAL PROTOCOL

Packed red cells were prepared in the laboratory from freshly drawn fetal blood centrifuged for 15 minutes at $7000 \mathrm{rpm}$. The animals were considered to be in basal state when two consecutive blood samples taken five minutes apart showed blood gas values within normal physiological limits. Then in five animals the haematocrit was raised in two steps, each consisting of an exchange transfusion of packed red cells with a haematocrit as high as $85 \%$. The packed cells were infused through the femoral vein while an equal quantity of blood was removed through the right carotid artery using an infusion withdrawal pump at the rate

Table 2 Changes observed in ventricular outputs and pulsatility indices with progressive increase in haematocrit

\begin{tabular}{|c|c|c|c|c|c|c|c|c|c|c|c|}
\hline$I D$ & Steps & $\begin{array}{l}\text { RVOw } \\
(\mathrm{ml})\end{array}$ & $\begin{array}{l}\triangle R V O w \\
(m l)\end{array}$ & LVOw (ml) & $\begin{array}{l}\triangle L V O w \\
(m l)\end{array}$ & $d a P I$ & $\triangle d a P I$ & $c P I$ & $\triangle c P I$ & $u P I$ & $\triangle u P I$ \\
\hline LAO & $1 \mathrm{~B}$ & 153 & & 102 & & 1.11 & & 2.0 & & 0.60 & \\
\hline NOR & $1 \mathrm{~B}$ & 235 & & 135 & & 1.45 & & 1.74 & & 0.33 & \\
\hline QUE & $1 \mathrm{~B}$ & 257 & & 234 & & 2.03 & & 1.91 & & 0.75 & \\
\hline TAN & $1 \mathrm{~B}$ & 112 & & 67 & & 1.26 & & 1.29 & & 0.51 & \\
\hline URU & $1 \mathrm{~B}$ & 193 & & 115 & & 0.81 & & 1.52 & & 0.40 & \\
\hline LAO & $2 M$ & 161 & 8 & 103 & 1 & 1.51 & 0.40 & 2.52 & 0.52 & 0.44 & -0.16 \\
\hline NOR & $2 \mathrm{M}$ & 165 & -71 & 101 & -34 & 1.03 & -0.42 & 1.81 & 0.08 & & \\
\hline QUE & $2 \mathrm{M}$ & 242 & -14 & 154 & -80 & 0.93 & -1.10 & 1.89 & -0.02 & 0.74 & 0.00 \\
\hline TAN & $2 \mathrm{M}$ & 108 & -5 & 55 & -13 & 1.39 & 0.13 & 1.71 & 0.42 & 0.62 & 0.10 \\
\hline URU & $2 \mathrm{M}$ & 109 & -85 & 121 & 6 & 1.02 & 0.21 & 1.60 & 0.08 & 0.84 & 0.44 \\
\hline LAO & $3 \mathrm{H}$ & 114 & -39 & 73 & -29 & 1.54 & 0.43 & 3.70 & 1.70 & 0.39 & -0.21 \\
\hline NOR & $3 \mathrm{H}$ & 133 & -102 & 89 & -46 & 0.87 & -0.58 & 2.18 & 0.45 & 0.35 & 0.02 \\
\hline QUE & $3 \mathrm{H}$ & 225 & -31 & 134 & -100 & 0.98 & -1.05 & 2.87 & 0.96 & 0.73 & -0.02 \\
\hline TAN & $3 \mathrm{H}$ & 74 & -39 & 34 & -33 & 1.21 & -0.05 & 3.63 & 2.34 & 0.64 & 0.13 \\
\hline \multirow[t]{7}{*}{ URU } & $3 \mathrm{H}$ & 131 & -63 & 104 & -11 & 0.98 & 0.17 & 1.65 & 0.13 & 0.78 & 0.38 \\
\hline & AVG (B) & 190.14 & & 130.7 & & 1.33 & & 1.69 & & 0.52 & \\
\hline & STD & 59 & & 62.6 & & 0.46 & & 0.29 & & 0.16 & \\
\hline & AVG $(M)$ & 156.8 & -33.4 & 106.7 & -24 & 1.18 & -0.15 & 1.91 & 0.22 & 0.66 & 0.10 \\
\hline & STD & 55.1 & 41.6 & 36 & 34.7 & 0.26 & 0.61 & 0.36 & 0.24 & 0.17 & 0.26 \\
\hline & $\operatorname{AVG}(\mathrm{H})$ & 135.3 & -54.9 & 86.8 & -43.9 & 1.12 & -0.22 & 2.81 & 1.11 & 0.58 & 0.06 \\
\hline & STD & 55.7 & 29.1 & 36.9 & 33.7 & 0.27 & 0.6 & 0.90 & 0.2 & 0.22 & \\
\hline $\begin{array}{l}\text { Friedman } \\
\text { ANOVA }\end{array}$ & $\mathrm{p}$ & 0.05 & & 0.05 & & $>0.05$ & & 0.015 & & $>0.05$ & \\
\hline
\end{tabular}

B, M and H: basal, moderate, and high haematocrit, respectively; RVOw: right ventricular output/kg; LVOw: left ventricular output/kg; daPI, cPI, and uPI: pulsatility index in descending aorta, carotid, and umbilical arteries, respectively. 

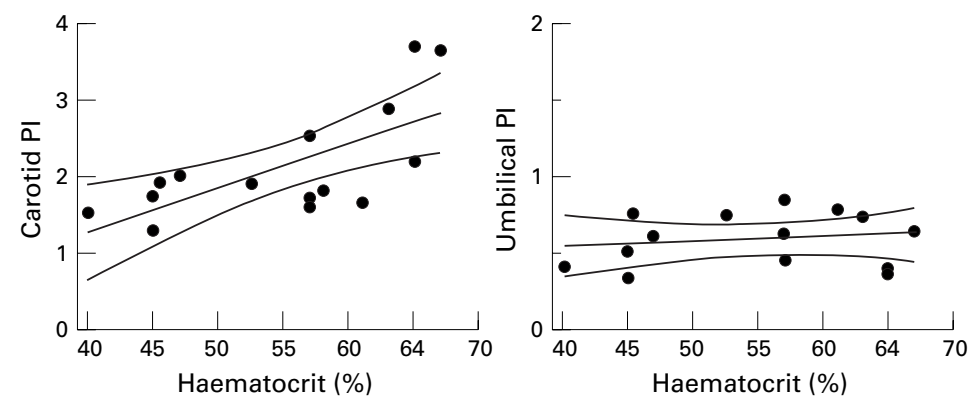

Figure 1 Correlations between haematocrit and pulsatility index (PI) in the carotid artery $\left(Y=-0.90+0.055 X, S_{Y / X}=0.56, r=0.67, F=10.7, p<0.01\right)$ and the umbilical artery $\left(Y=0.42+.003 X, S_{Y \mid X}=0.18, r=0.15, F=0.3 ; n s\right)$. Significant positive correlation was found only between haematocrit and the PI in the carotid artery.

of $15 \mathrm{ml} / \mathrm{min}$. In three other fetuses the same protocol was followed except that fetal blood with a haematocrit similar to that of the recipient fetus was infused. These fetuses were used as controls. At each step, $180 \mathrm{ml}$ of blood (with raised or normal haematocrit) was infused, equivalent to an exchange of about $50 \mathrm{ml} / \mathrm{kg}$. After a recovery period of about 15 minutes, Doppler recordings and blood samples were then obtained. The whole study lasted about three hours.

Data are presented as means \pm one standard deviation. The Friedman ANOVA for repeated measurements was used to establish significant variation in haematocrit. Correlations between haematocrit and pulsatility indices in the carotid artery, descending aorta, and umbilical artery were tested using linear regression analysis. A probability of $\mathrm{p}<0.05$ was considered significant.

\section{Results}

The average weight of the fetuses was 3.44 (0.48) kg. Table 1 gives the haematocrit, viscosity, and blood gases on the eight lambs at basal state and the changes observed after the two exchange transfusions. The haematocrit rose significantly in the experimental group from 44 (3) to $64(2) \%$ while there was no significant change in the control group. The rise in haematocrit did not alter the $\mathrm{pH}, \mathrm{PaO}_{2}$, or $\mathrm{PaCO}_{2}$. The progressive increase in haematocrit was associated with a significant increase in blood viscosity from $5.3(0.3)$ to 9.6 (1.6) cps. Mean arterial pressures remained stable, averaging 63,68, and $67 \mathrm{~mm} \mathrm{Hg}$ at the three concentrations of haematocrit. Table 2 shows changes observed in the ventricular outputs and pulsatility indices. The output of the two ventricles fell while the red cell mass increased. At the end of the last exchange transfusion, combined cardiac output had fallen to $30 \%$ of its initial value. In the control group combined cardiac output remained stable at 437 and 431 $\mathrm{ml} / \mathrm{kg} / \mathrm{min}$, at the beginning and at the end of the experiments, respectively. Heart rate did not change significantly throughout the study. The changes in haematocrit had no effect on the pulsatility indices in the descending aorta and umbilical artery (table 2). The pulsatility indices of the control group were similar to those of the high haematocrit group in the descending aorta and the umbilical artery, but for the carotid artery this was only the case at baseline values. Indeed, a significant positive correlation was found between haematocrit and PI of the carotid artery in the experimen-
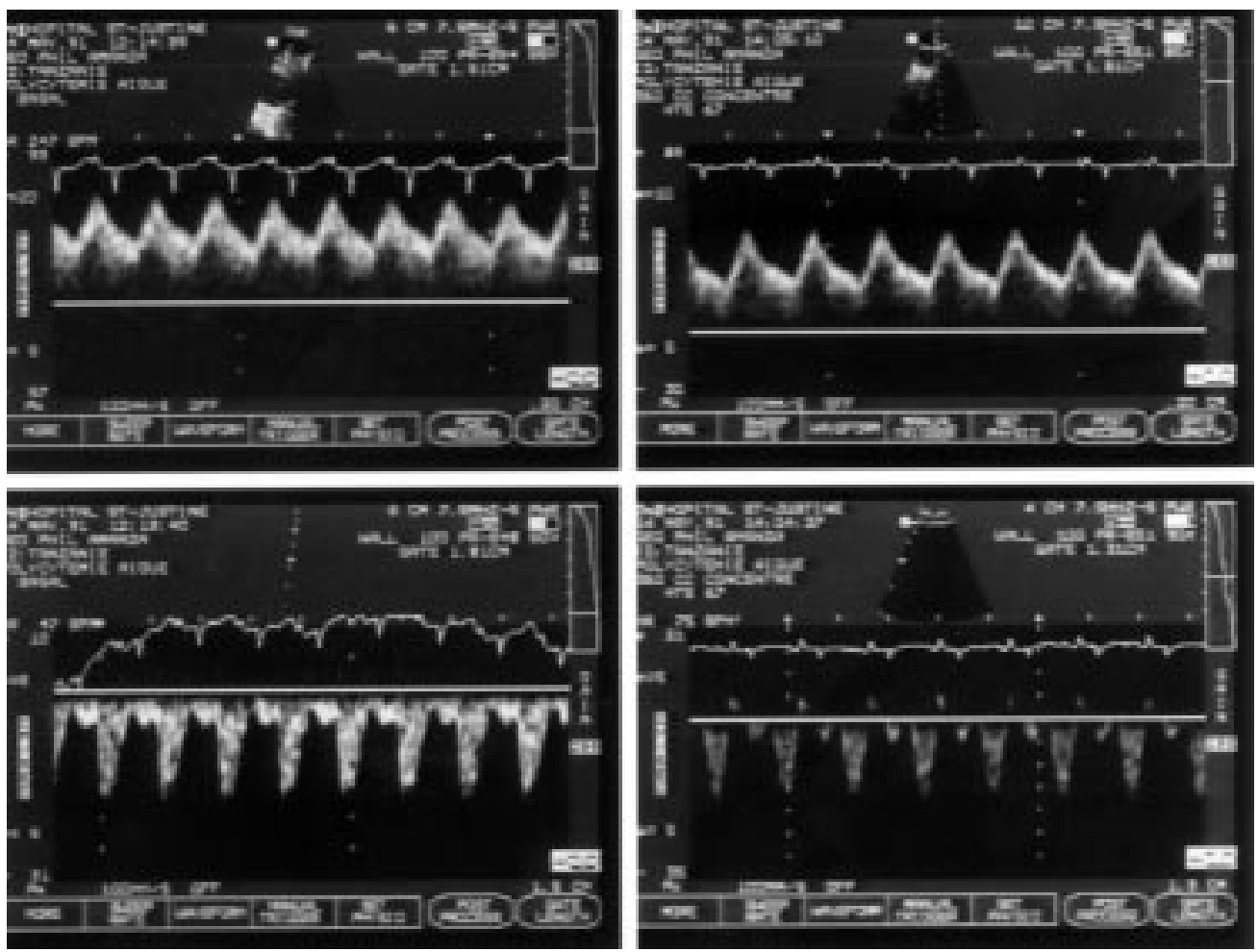

Figure 2 Examples of Doppler velocity recordings in the umbilical artery (top) and carotid artery (bottom) of a fetal lamb. Recordings at an haematocrit of $45 \%$ to the left and at $67 \%$ to the right. Very little change is recorded in the umbilical artery but a marked decrease in diastolic velocities is observed in the carotid artery with the higher haematocrit. 
tal group ( $\mathrm{r}=0.67, \mathrm{p}<0.01$ ) (fig 1 ). This was essentially due to a decrease and sometimes to a complete disappearance of late diastolic flow velocities in the carotid artery in the presence of higher haematocrit concentrations (fig 2).

\section{Discussion}

Ultrasound technology is now increasingly used in the assessment of circulatory dynamics in human fetuses. The application of the same technique in this experimental study was planned to facilitate incorporation of the results into the clinical setting. With this in mind, exchange transfusions were made with fetal blood, thus taking into account its lower plasma fibrinogen concentration and the different rheological properties of fetal erythrocytes. ${ }^{7}$ To obtain rapid assessment of changes in the peripheral circulation using the Doppler technique, the fetuses had to be brought out of their amniotic sacs. Despite the known drawbacks of this, it was possible to maintain adequate oxygenation and stable haemodynamic conditions for the three hours needed for the completion of the experiments, as confirmed by the control group.

A fall in cardiac output has been documented, with raised haematocrit in both adults ${ }^{3}$ and during the immediate postnatal period. ${ }^{4}$ The same observation was made in our group of fetuses. Another constantly reported finding is a rise in systemic peripheral resistance. Both the lower output and the higher resistance have been related to the increased viscosity and the sluggish peripheral circulation, leading to a decrease in venous return. The increase in arterial $\mathrm{O}_{2}$ content associated with the polycythemia could be another factor; indeed, in dogs an increase in tissue oxygen delivery without a change in haematocrit causes arteriolar vasoconstriction and raises total peripheral resistance. ${ }^{8}$ In our study the PI was used to assess downstream vascular impedance. ${ }^{9}$ No change was observed in the PI of the umbilical artery, confirming previous reports. ${ }^{12}$ This presumably reflects the relative inertia of the placental vascular bed. The absence of change in the PI in the descending aorta, on the other hand, while reflecting the dominant role of placental circulation in the downstream resistance of the systemic circulation, does not rule out localised variation of resistance in vascular beds such as the renal, mesenteric, and lower limb arteries. We did not investigate those networks.

Investigations of both humans ${ }^{1011}$ and animals ${ }^{12} 13$ have consistently shown that polycythemia decreases cerebral blood flow. The increase in both blood viscosity ${ }^{14}$ and arterial $\mathrm{O}_{2}$ content ${ }^{15}$ which are associated with polycythemia, could be responsible for an increase in vascular resistance and cause the fall in cerebral perfusion. In the present study the velocimetry of the carotid artery was investigated as this artery has shown itself to be a reliable indicator of dynamic events occurring in the cerebral circulation in the lamb. ${ }^{16}$ The fact that a significant increase in PI was observed in the carotid artery of our fetal lambs strongly suggests that an increase in cerebral vascular resistance was also created by the increase in haematocrit in our experimental preparations. The design of our study did not allow us to establish whether the increase in cerebral vascular resistance was due to the blood hyperviscosity or the increase in arterial $\mathrm{O}_{2}$ content, or both.

These observations could have some important clinical implications. In fetuses at risk of major variations in their haematocrit, our results confirm that investigation of the flow velocity patterns in the descending aorta or the umbilical artery is of little use. The cerebral circulation, on the other hand, seems to be the vascular network where clinically significant velocimetric changes could be observed. This should be particularly conspicuous in the twin to twin transfusion syndrome as the anaemic fetus, in addition to his hyperdynamic cardiac condition, ${ }^{17}$ should show signs of lower cerebral vascular resistance and low cerebral PI due to the lower oxygen carrying capacity and viscosity of his blood while the polycythemic twin, according to our results, should be expected to have a raised middle cerebral artery PI. In addition to the polycythemia, however, the recipient twin can also be expected to be hypervolaemic. Previous reports on Doppler changes in the middle cerebral artery of recipient twins are conflictual, showing either a fall ${ }^{18}$ or no change ${ }^{19}$ in the pulsatility indices of the middle cerebral arteries of the recipient twins. None of the two studies gave actual values of the haematocrit or viscosity of their subjects either before or after birth. Further investigations are obviously needed to evaluate the relevance of our experimental findings in the human fetus.

This study was supported by grants from the Quebec Heart Foundation and the Canadian Medical Research Council.

1 Fairlie FM. Lang GD, Lowe GG, Walker JJ. Umbilical artery flow velocity waveforms and cord blood viscosity. Am F Perinatol 1991;8:239-43.

2 Giles WB, Trudinger BJ. Umbilical cord whole blood viscosity and the umbilical artery flow velocity time waveforms: a correlation. Br $\mathcal{F}$ Obstet Gynecol 1986;93:466-70.

3 Murray JF, Gold P, Johnson BL. The circulatory effects of hematocrit variations in normovolemic and hypervolemic dogs. F Clin Invest 1963;4:1150-9.

4 Fouron JC, Hébert F. The circulatory effects of hematocrit variations in normovolemic newborn lambs. I Pediatr 1973;82:995-1003.

5 Bonnin P, Fouron JC, Teyssier G, Sonesson SE, Skoll A. Quantitative assessment of circulatory changes in the fetal aortic isthmus during progressive increase of resistance to umbilical blood flow. Circulation 1993;88:216-22.

6 Gosling RG, King DH. Ultrasonic angiology. In: Marcus Q W, Adamsson L, eds. Angiology, arteries and veins. Edinburgh: Churchill-Livingstone, 1975:61-98.

7 Riopel L, Fouron JC, Bard H. Blood viscosity during the neonatal period. The role of plasma and red blood cell type. F Pediatr 1982;100:449-53.

8 Liard JF, Kunert MP. Hemodynamic changes induced by low blood oxygen affinity in dogs. Am $\mathcal{f}$ Physiol 1993;264:R396-R401.

9 Trudinger BJ, Stevens D, Connelly A, et al. Umbilical artery flow velocity waveforms and placental resistance: the effect flow velocity waveforms and placental resistance: the effect Gynecol 1987;157:1443-8.

10 Thomas DJ, Marshall J, Ross Russell RW, et al. Effect of haematocrit on cerebral blood flow in man. Lancet 1977;ii:941-3.

11 Rosenkrantz TS, Oh W. Cerebral blood flow velocity in infants with polycythemia and hyperciscosity: Effects of partial exchange transfusion with plasmanate. $\mathcal{F}$ Pediatr 1982;101:94-8.

12 Fan FC, Chen RYZ, Schuessler GB, Chien S. Effects of hematocrit variations on regional hemodynamics and oxygen transport in the dog. Am $\mathcal{F}$ Physiol 1980;238:H545H52.

13 Rosenkrantz TS, Stonestreet BS, Hansen NB, Nowicki P, $\mathrm{Oh}$ W. Cerebral blood flow in the newborn lamb with polycythemia and hyperviscosity. $\mathcal{F}$ Pediatr 1984;104:27680. 
14 Massik J, Tang YL, Hudak ML, Koehler R, Traystman RJ, Douglas Jones M. Effect of hematocrit on cerebral blood flow with induced polycythemia. I Appl Physiol 1987;62:1090-6.

15 Peeters LLH, Sheldon RE, Jones MD, Makowski EL, Meschia G. Blood flow to fetal organs as a function of arterial oxygen content. Am $\mathcal{f}$ Obstet Gynecol 1979;135:637-46.

16 van Bel F, Roman C, Klautz RJM, Teitel DF, Rudolph AM Relationship between brain blood flow and carotid arterial flow in the sheep fetus. Pediatr Res 1994;35:329-33.
17 Lachapelle MF, Leduc L, Côté JM, Grignon A, Fouron JC. Potential value of fetal echocardiography in the differential diagnosis of twin pregnancy with presence of polyhydramnios-oligohydramnios syndrome. Am $\mathcal{F}$ Obstet Gynecol 1997;177:388-94

18 Hecher K, Ville Y, Nicolaides KH. Fetal arterial Doppler studies in twin-twin transfusion syndrome. $\mathcal{F}$ Ultrasound Med 1995;14:101-8.

19 Rizzo G, Arduini D, Romanini C. Cardiac and extracardiac flows in discordant twins. Am $\mathcal{F}$ Obstet Gynecol 1994;170:1321-7. 